\title{
THE EDITORIAL BOARD
}

With the large number of papers being submitted on exercise physiology, it has become necessary to increase the size the Editorial Board, and we are delighted to welcome three new members; Professor David Taylor, F.R.C.S. of the Department of Human Physiology and Surgical Science, Royal College of Surgeons, London; Professor Harfi Thomason, Ph.D., of the Department of Physical Education and Sports Sciences, University of Loughborough; and Mas. Margaret John, M.C.S.P., who is on the Editorial Board of "Physiotherapy", and former chairman of the C.S.P.'s Public Relations Committee.

The Board, with its new members, had a joint meeting in April with the Executive Committee of B.A.S.M. to discis the future of the Journal, especially in view of a large increase in advertising revenue promised, and a more stabfe financial situation of B.A.S.M. Many interesting points were discussed regarding possible changes in format and additional separate sections in each number, tighter refereeing, encouragement for more original articles, especially ih the clinical field, and the commission of special review articles by recognised experts. One of the main difficulties facing us is due to the wide variety of interests of our readers, which really prevents concentration on super-specialist articts in one or two fields only. The sports scientist interested in hypothermia in canoeing will resent articles devoted only $₫ 0$ improved operative techniques in tendon surgery, and the oxygen uptake of American school children may seem to have little relevant fact to help the physiotherapist looking after a professional football team's injuries. The need ₫o combine popular education with scientific merit is a most difficult task, and the possibility of running two publications has been raised on previous occasions. This would, of course, lead to a considerable rise in subscriptions, a course we are most reluctant to contemplate. One suggestion that can be considered more seriously is a section devoted to abstracts of major articles from other journals. For this, extra editorial help would be needed, especially for translation from French; Italian, German, Finnish, Dutch, Spanish, Portugese, Turkish, Czech. Any offers?

It was also felt that there should be encouragement for many more short reports, of some 1,200 words, or less if figure or table were to be included. Case reports, pilot experiments, innovations in treatment or investigation, are suitable topics for this type of short article.

We cannot hope to compete with the well established scientific journals with their highly specialised materi商. Surgeons will continue to submit their major papers to Brit. J. Surgery, orthopaedic surgeons to Bone and Joint, and physiologists to J. Physiol. We see our place as giving a publication outlet for original work APPLIED TO EXERCI\$E AND SPORT, and must include the promotion of health as well as the treatment of the sick. There is no objection to the submission of work directly related to sports medicine even if operations or investigations have been publisheed elsewhere in another context.

\section{B.A.S.M.'S SILVER JUBILEE}

This is the twenty-fifth year of the British Association of Sport and Medicine, and to celebrate the occasion a special number of the journal will be published later this year, devoted exclusively to papers contributed by the members $\overline{\partial f}$ the Editorial Board, on a topic of the author's own choice.

Our Association started as a gathering of doctors, mostly medical advisers to governing bodies of sport, but a few other interested doctors, and one or two national coaches brought in as Associates; a total of 88 members. By 1962 membership had doubled, and during the three subsequent years, with the extension of B.A.S.M. activities to areas outside London, membership rose to 436 , and to 628 by 1971 . There was a slow but steady increase up to 1976, an of more rapid recruitment during the past year and a half. 130 new members have been elected during the first five months of 1978, and several applications are received every week.

Not only has membership increased by $\times 10$ since 1953; the annual subscription has as well. Originally fit membership was 10/- a year, raised to a guinea in 1962, and gradually until the present rate of $£ 5$ was fixed in 19 65 (and we hope to hold it there, despite inflation). The financial turnover for 1953 was $£ 63$, and for $1977 £ 6,700$ for $t$ No. 1 general purposes account alone.

In the early 1960's a special number of "Physical Education" was devoted to sports medicine, but in 1964 W" started our own publication, the "Bulletin of the British Association of Sport and Medicine" edited by Roy James. \$n 


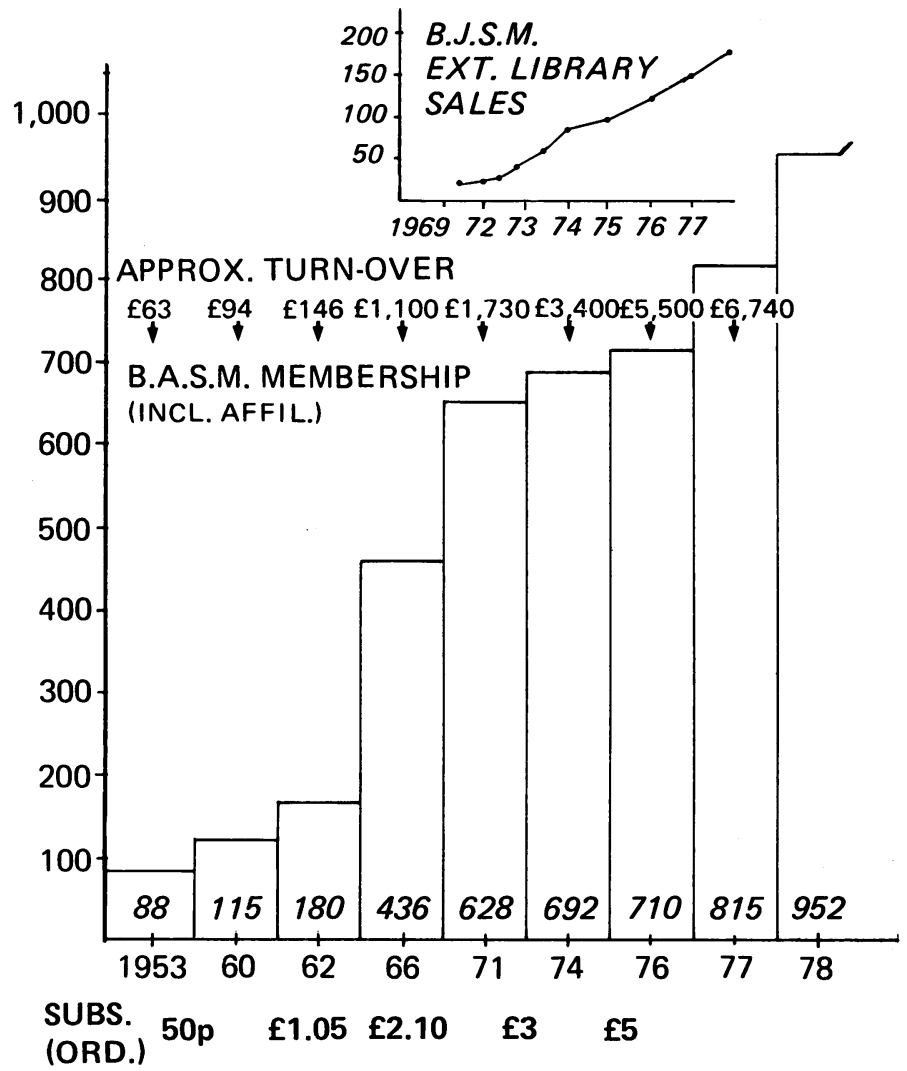

1967, John Williams and the present editor took over joint editorial duties, and later, with John Williams' increasing international commitments, he had to relinquish this job. The title "British Journal of Sports Medicine" was registered at Stationers' Hall in 1968. At that time a very few journals were supplied to libraries, but by 1977 external library sales brought in $£ 1,500$, and several bad debts, recovered later, are not included in this figure.

The regional organisation of B.A.S.M. should be of great help to those whose commitments and finances make journeys to London difficult, and for many years the most successful Scottish Area has run regular meetings all over the country, provided most of the medical services for the Edinburgh Commonwealth Games, and now started up a Sports Medicine clinic at the Meadowbank Stadium in Edinburgh. Attempts to run similar organisations in the North East were beset by the illnesses and deaths of Michael Keating, and later Adrian Bain. The North West was active at one time, but the departures of John Brooke and later Harry Thomason to professorial chairs left Don Masterson unsupported, until such time as new enthusiasts can be recruited from all the relevant professions again in that area. During April two new Areas have been established at well-supported meetings in Leeds and Cardiff. The officers elected are listed in the Bulletin section of this number of the journal.

\section{VOLUME 12, NUMBER 2}

The current number, contains a second paper from the team at the Deaconess Institute in Finland, describing a lesion of the iliotibial tract that few orthopaedic surgeons or rheumatologists have reported from the United Kingdom (though the syndrome is not unknown here), but seems to be associated with running in very cold environments. Any short reports, or full articles on a series of iliotibial tract friction syndromes, would be appreciated by the Editor with a view to publication. A second paper from Manchester on the progress of young swimmers is given by Kellett, Willan and Bagnall, and is a good example of the multi-disciplinary teamwork that is so necessary not only in sports medicine, but in many other branches of medicine also. Pulse and respiratory recovery are compared in medical and physical education students in India by $\mathrm{De}$ and his co-workers, and some interesting biochemical studies are reported by van Dam with regards to Vitamin B group metabolism in athletes, and to the production of insulin by exercise, which sheds 
some light on exercise-induced hypoglycaemia. The B.A.S.M.'s annual accounts and reports from 1977 are included together with a long list of new members elected. Reports on other activities of the Association are described in the Secretary's Column in the Bulletin section.

The main aims of the Editorial Board and Executive Committee are to bring about improvements in the contents and presentation of the Journal, by gradual evolutionary processes, rather than by a complete revolution, and bearing mind that the British Journal of Sports Medicine reflects the aims and interests of the British Association of Sport an Medicine, in all its many facets.

\section{PHYSICAL EDUCATION INDEX}

This new American publication lists the authors, titles and references of articles or abstracts published in English from: large selection of journals, including B.J.S.M., that contain material relevant to physical education and sport. The Inde $\vec{x}$ is published by the BenOak Publishing Company, Box 474, CAPE GIRARDEAU, Missouri 63701, U.S.A., from who鱼 details, cost etc., can be obtained.

\section{OBITUARY}

Dr. JOHN ALEXANDER CURRIE, M.B., B.S., M.R.C.S., L.R.C.P.

John Currie qualified at London University in 1937, and was in a single-handed general practice until his retirement in 1975. He lived and practised from his home in South Stoke, near Reading, and was keenly interested in local and national equestrian events. He joined B.A.S.M. in 1966, and attended many meetings of the Association. At the time of the World Congress of Sports Medicine held in Oxford in 1970, he undertook the difficult and responsible job of press relations officer at extremely short notice, when the person appointed for the purpose defected. As this was the first Sports Medicine World Congress to be held in the United Kingdom, we had no precedent to follow; neither had the Press, and the full and careful reporting of the congress, the personal interviews, the press conferences, and radio and television interviews were all handled by John with the greatest tact and efficiency. He was always willing to undertake any job he was given, and we shall all miss him a great deal. We extend our deepest sympathy to his widow and his large family.

H. E. Robson

\section{OBITUARY}

\section{IAN MELVILLE STEWART - 1923-1978}

Ian Stewart qualified in 1946 in St. Andrew's University. After his year of residency in Dundee Royal Infirmary he saw National Service in Kenya and Somaliland. He resumed his surgical and orthopaedic training in Dundee Royal Infirmary and the Bridge of Earn Hospital. Gaining his Fellowship in 1953 he became Lecturer in Orthopaedics in Dundee Royal Infirmary and Senior Registrar to Professor Smellie. He joined the Orthopaedic Department of Law Hospital in November, 1961 where he maintained his keen interest in surgery of the hand. He had widespread clinical interests including sports injuries and latterly in an attempt to prevent pressure sores he developed a total body support system of fluidising sand. A devoted family man, he will be sadly missed by his wife Joan and their three daughters, Janet, Briar and Joanna.

J. Garden 